\title{
Financial benchmarking on dairy farms: Exploring the relationship between frequency of use and farm performance
}

\author{
G. Ramsbottom, ${ }^{1 *}$ D. Läpple, ${ }^{2}$ and K. M. Pierce ${ }^{3}$ \\ ${ }^{1}$ Teagasc, Oak Park, Co. Carlow, Ireland R32 XE12 \\ ${ }^{2}$ School of Business and Economics, National University of Ireland Galway, Galway, Ireland H91 F677 \\ ${ }^{3}$ School of Agriculture and Food Science, University College Dublin, Belfield, Dublin 4, Ireland D04 W6F6
}

\begin{abstract}
The importance of financial benchmarking has increased in recent years as European Union milk quota abolition has facilitated rapid change in the dairy sector. This study evaluates the association between usage frequency of a financial benchmarking tool [Profit Monitor (PM)] and farm changes on spring-calving pasture-based dairy farms. To this end, physical and financial data for 5,945 dairy farms, representing 20,132 farm years, for the years 2010 to 2018 were used. Farms were categorized by frequency of annual financial benchmarking over the 9-yr period into frequent PM users (7-9 yr), infrequent PM users (4-6 yr), low PM users $(1-3 \mathrm{yr})$, and nonusers. We use a mixed model framework and econometric models to characterize farms and to explore characteristics and determinants of economic performance and user groups. The most frequent users of the financial benchmarking tool had the greatest increase in intensification (measured by change in farm stocking rate), productivity (measured by change in milk production per hectare), and financial performance (measured by change in farm gross output and net profit per hectare) across the study period. Infrequent and low PM users of the benchmarking tool were intermediate for all variables measured, whereas nonusers had the least change. Empirical results indicated that economic performance was positively associated with dairy specialization and pasture utilization for all groups. Despite considerable fluctuations over the observation period, the overall change in total farm net profit between 2010 and 2018 was greatest for the frequent PM users (an increase of $70 \%$, or €37,639), followed by farms in the infrequent PM user category (a $71 \%$ increase corresponding to an increase of $€ 28,008$ in net profit); meanwhile, low PM user and nonuser categories showed increases of $69 \%(€ 26,270)$ and $42 \%$
\end{abstract}

Received May 5, 2020.

Accepted September 28, 2020.

*Corresponding author: george.ramsbottom@teagasc.ie
$(€ 10,977)$, respectively. The results of this study also clearly indicated the existence of a strong positive association between frequency of financial benchmarking and greater technical and financial efficiency. The econometric analysis revealed that financial benchmarking users are more likely than nonusers to have larger herds, and that regional differences exist in usage rates. Finally, the study concludes by suggesting that the development of simplified financial benchmarking technologies and their support are required to increase benchmarking frequency, which may also help to facilitate a more sustainable and resource efficient dairy industry.

Key words: dairy, pasture-based, financial benchmarking, technical, financial

\section{INTRODUCTION}

Abolition of the European Union (EU) milk quota in 2015 precipitated considerable restructuring within the EU dairy sector. Milk production has significantly increased in some countries, such as Ireland, Poland, and the Netherlands, but declined in others, such as France and Romania (Eurostat, 2020). In general, milk production has expanded in countries with a comparative advantage, which are often regions that favor pasture production. For example, Irish milk production, which is based on pasture-based systems, has increased by $67 \%$ between 2009 and 2019, with almost 3 quarters of this increase (73\%) occurring since 2015 (CSO, 2020b). Moreover, the Irish dairy herd has increased by $39 \%$ during the same time 10-yr time period (CSO, 2020a).

Although considerable variation in production costs is observed on dairy farms across continental Europe (IFCN, 2019), Ireland has one of the lowest costs of producing milk worldwide (Dillon et al., 2008). The principal reason for the low production costs that prevail in Ireland is that milk production is primarily based on seasonal calving pasture-based systems (Dillon et al., 2008). Grazed grass is the lowest-cost feed available, and farmers aim to optimize its use in the diet of the lactating dairy cow (Dillon et al., 1995). A wide vari- 
ety of factors affect pastoral dairy herd performance, including region (Patton et al., 2012; Ramsbottom et al., 2015), with southern and eastern regions of Ireland reporting greater production per cow. Similarly, higher concentrate supplementation rate, although associated with increased production costs in pasture-based systems (Ramsbottom et al., 2015; Neal and Roche, 2020), is also associated with greater milk production per cow, and cows with greater genetic merit for milk production produce the greatest yields (Ramsbottom et al., 2012; O'Sullivan et al., 2019).

Generally, Irish and EU dairy farmers are increasingly exposed to world market prices, with increasing fluctuation in milk prices observed since 2006 (Teagasc, 2015). Careful financial monitoring is particularly important for pasture-based systems because low-cost grazing systems tend to be inflexible to milk price volatility. The fixed costs associated with pasture production have already been incurred, and thus there is little scope for further cost reduction. Hennessy et al. (2015), for example, reported that farmers who financially benchmark have, on average, lower production costs and are more profitable than the national average. Even among dairy farmers who benchmark regularly, Ramsbottom et al. (2020) observed a 150\% difference in 8-yr average farm net profit per hectare between the highest and lowest profit quartiles.

A variety of tools are available to farmers to determine their costs of production and facilitate peer-topeer benchmarking, including Farmbench in the United Kingdom (AHDB, 2020), Dairybase in New Zealand (DairyNZ, 2020), and Redsky in New Zealand, Australia, and Argentina (Dowie, 2020). Teagasc, the Irish semistate advisory, research, and education agency, produces an analysis of dairy production costs on an annual basis using both the Profit Monitor (PM) and the National Farm Survey (NFS). Profit Monitor completion allows users to analyze and benchmark their production costs and profitability against their contemporaries and, when completed regularly, allows them to monitor trends in performance on a multiannual basis (Teagasc, 2019a). However, despite initiatives by the Irish Department of Agriculture to increase the number of dairy farmers completing PM in the 2010 to 2015 period through financially incentivizing extension programs that required completing PM annually (Läpple and Hennessy, 2015), only approximately $14 \%$ of dairy farmers (approximately 2,500) complete one each year (Teagasc, 2019a). Participation in the programs was voluntary. Farmers could complete PM without participating in or while participating in the extension programs. Either option is likely to be influenced by similar unobserved factors such as farmer's ability or economic motivation. The low benchmarking rate is consistent with previous research from Ireland (Byrne et al., 2003) and New Zealand (Parker, 1999). Moreover, frequency of PM completion differs considerably between farms, ranging from none to regular completion over several years. How and whether this difference in frequency of financial benchmarking affects farm performance remains an open question, with the studies of Candler and Sargent (1962) and Parker (1998) suggesting that there is little evidence of an association between financial benchmarking and farm performance. Indeed, Ferris and Malcolm (1999) suggest that the use of multiple indicators such as cash flow, profitability, and net worth change is necessary when evaluating any business.

In this study, we explore how frequency of engagement with a financial benchmarking tool affects farm physical and financial performance, and assess characteristics associated with different levels of PM engagement. We also discuss implications for environmental sustainability and resource use. The specific objectives of this study, using a large farm physical and financial database, were (1) to characterize the physical and financial trends from 2010 to 2018 on spring-calving pasture-based dairy farms, (2) to describe the farms categorized by frequency of use of PM and explore factors associated with economic performance for each farm category, (3) to document the trends over a 9-yr period for the different PM use categories, and (4) to identify the drivers for the different PM user categories.

\section{MATERIALS AND METHODS}

\section{Data}

In this study, we combined PM and NFS data to explore the associations between financial benchmarking and farm physical and financial performance. Both data sets are described subsequently. In relation to PM data, information (both technical and financial) is provided by the farmer through the completion of an input sheet, which is typically checked and then entered by the farmer's advisor (Hennessy et al., 2015). The data are held centrally, and secure access to the database is provided to facilitate the input of data and viewing of reports (Ramsbottom et al., 2015). The results generated are not nationally representative, as the farms included in the annual data set are self-selecting and do not proportionally represent the entire farming population.

The NFS fulfills Ireland's statutory obligation to provide data on farm output, costs, and income to the European Commission. A random sample of approximately 1,000 farms is selected annually, representing a farming population of approximately 90,000 farms, 
with a weighting factor assigned to each so that the results of the survey are representative of the national population of farms (Teagasc, 2020). Farmers participating in the NFS are surveyed through a series of face-to-face interviews with a professional data collection team. Although the NFS distinguishes between 6 dominant farming systems in Ireland (i.e., dairy, 2 cattle systems, sheep, arable, and mixed livestock), this study was restricted to dairy farms. The NFS includes approximately 300 dairy farms in each year, and we extracted nonusers from the NFS data.

In the present study, we extracted data from PM and NFS databases on farm physical data and financial performance for the years 2010 to 2018. The overall data includes 19,416 observations from 5,688 individual farms from the PM database and 716 observations from 257 individual farms from the NFS.

\section{Variable Calculation}

In relation to farm physical data, monthly animal numbers of cows, replacement heifers, and dry stock (i.e., beef cattle and sheep) were averaged across each calendar year to determine their average livestock units $(\mathbf{L U})$ in both data sets. The animal categories included in the calculation of total LU were dairy cows, replacement heifers, and dry stock. Farm stocking rate (SR) was calculated by dividing the total LU on the farm by the number of hectares of forage area (pastureland and forage crop area combined) on the farm. Total farm milk production was divided by total dairy cow LU present on the farm to calculate average milk yield per cow and multiplied by farm SR to calculate milk produced per hectare. Average annual fat and protein percentages were obtained from the milk processor returns and used to calculate milk solids yield (i.e., yield of fat and protein expressed in kilograms). Liters of milk produced per kilogram of feed used was calculated by dividing the liters of milk produced per cow by the kilogram of feed fed per cow. This serves as a measure of resource efficiency. Pasture DM utilization were calculated by back calculating DM intake per cow using data for milk yield and estimated cow liveweight. Then, the estimate of pasture DM consumed per cow was calculated by deducting the DM content of concentrate feed and purchased forage fed per cow. Finally, pasture DM per hectare was calculated by multiplying the estimate of pasture DM consumed per cow by the farm SR (Ramsbottom et al., 2015). Pasture utilization serves as a measure of environmental sustainability, as the amount of grazed grass is an important greenhouse gas mitigation measure (Lanigan and Donnellan, 2019).

In relation to financial data, gross output per farm was calculated by combining the value of milk, crop, and stock sales, and the standard value of calf transfers to beef and replacement heifer enterprises. Then, the cost of purchased stock or the standard value of in-calf heifers transferred from the farm's replacement heifer enterprise was deducted and an adjustment made, where applicable, for stock inventory change. Variable costs recorded in both the PM and NFS included feed and fertilizer, breeding and veterinary costs, and farm contractor costs as well as other variable costs including milk recording, parlor expenses, and bedding costs. The cost of dairy cow feed was allocated directly to the dairy enterprise. Fixed costs recorded included machinery, hired labor, electricity, phone, and transportation expenses as well as the costs of leasing land and milk quota. Net profit was calculated as the profit remaining after all variable and fixed costs were deducted from the gross output. Net profit was expressed per hectare farmed by dividing total farm net profit by the total number of hectares farmed. Gross output, total variable costs, and total fixed costs were calculated using a similar approach. The economic values presented are in nominal terms, as our main interest lied in comparing changes over time across PM user groups, which were all subject to the same input and output price changes.

Finally, 3 geographical regions were identified, which differ in their seasonal production of pasture and rainfall similar to those detailed in Teagasc (2019b).

\section{Data Analyses}

Analyses were undertaken using a mixed model framework in PROC MIXED (SAS, 2005). Fixed effects included in the 3 analyses were farm year, PM frequency completion category, and the interaction between year and category of PM frequency completion. The first series of analyses estimated the annual least squares means, and thus the longitudinal trends in physical and financial performance over the study period. The second series of analyses quantified the association between category of PM frequency completion over the 9-yr observation period and the various physical and financial characteristics. The third series of analyses quantified the association between category of PM frequency completion and the various physical and financial characteristics for each year.

To get insight on specific factors that are associated with economic performance, we estimated a panel data fixed effects model divided by the 4 PM user categories. We let $y_{i t}$ be farm gross margin per hectare and $X_{i t}$ be a matrix of explanatory variables comprising farm size, specialization, pasture utilized, meal fed, and their squared terms. We estimated the following equation to reveal associations between economic performance and farm physical factors: 


$$
y_{i t}=\beta_{1}+\beta_{2} X_{i t}+\beta_{3} T_{t}+u_{i}+\varepsilon_{i t},
$$

where $\beta$ are the coefficients to be estimated, $T_{t}$ is a year fixed effect, $u_{i}$ is a farm specific effect (that is "differenced away" in fixed effects estimation), and $\varepsilon_{i t}$ is an idiosyncratic error.

In our last step of the data analysis, we applied a multinomial logit model that separated individual farms into the 4 distinct PM user groups to explore the factors that distinguish among these groups. The multinomial logit model is an extension of the binary logit model, in which the response variable has more than 2 unordered qualitative responses. More formally, the outcome variable $y_{i}$ can take on values $j=1,2, \ldots, J$, with $J$ being a positive integer that corresponds to the number of outcomes (categories). In this application, we have 4 categories: nonusers of $\mathrm{PM}(j=1)$, low PM users $(j=2)$, infrequent PM users $(j=3)$, and frequent PM users $(j=4)$. The determinants associated with each category are contrasted to the base category (i.e., nonusers of PM). Specifically, we are interested how, all other things being equal, changes in an explanatory variable $x$ affect the outcome probabilities $\operatorname{Pr}\left(y_{i}=j \mid x\right)$ $j=1,2, \ldots, J$ (Wooldridge, 2010). As we had a 9-yr period, we estimated a pooled model with year fixed effects and cluster standard errors at the farm level. We include farm characteristics and regional dummy variables as explanatory variables and also control for year effects. Our main aim was to reveal significant differences between the 3 categories of PM frequency use and nonusers of PM.

\section{RESULTS}

\section{Interyear Variability in Physical and Financial Performance on Pasture-Based Dairy Farms}

Summary statistics, calculated through the PROC MIXED procedure in SAS, for a range of performance measures for the sample farms over a 9-yr period are presented in Table 1. This table provides least squares means, and associated standard deviations are reported in the Supplemental Table S1 (https://doi.org/10 .3168/jds.2020-18843). Overall, we observed significant changes in all variables over the study period and significance levels are indicated in the last column of Table 1. More specifically, there were increases in farming scale, specialization, and intensity during the 9-yr study period. The total area farmed increased over the period by $12 \%$, whereas the scale of the dairy enterprise (measured in herd size) increased by $36 \%$, which implied an increase from 78 to 106 cows $(P<0.001)$. The farms also became more specialized in dairying over the study period as the proportion of dairy cows increased by $5.1 \%$ over the 9 -yr period $(P<0.001)$ and comprised $70.1 \%$ of all animals on the study farms in 2018. In relation to intensity, SR increased $(P<0.001)$ from 2.02 in 2010 to $2.19 \mathrm{LU} /$ ha in 2018.

Production increases were also evident on study farms over the observation period. For example, milk solids increased per cow and per hectare farmed $(P<0.001)$ by $15 \%$ and $26 \%$, respectively. Milk fat and protein content increased by $7.2 \%$ and $3.4 \%$, respectively, per cow. Milk produced per kilogram of feed consumed was least in $2018(P<0.001)$, reflecting reduced pasture DM production following a prolonged summer drought. Furthermore, pasture DM utilized per hectare, despite varying between years due to the effect of weather, increased $(P<0.001)$ from 7.6 to $8.1 \mathrm{t}$ of $\mathrm{DM} /$ ha and was $6.6 \%$ greater $(P<0.001)$ in 2018 than in 2010 . As a consequence of both higher milk production per cow and per hectare, production of total fat plus protein per farm increased by $57 \%$ during the study period.

Both farm output $(P<0.001)$ and costs $(P<0.01)$ increased between 2010 and 2018 (Table 1). As a result of increasing intensification and varying milk price, gross output $(€ /$ ha) was lowest $(P<0.001)$ in 2010 at $€ 2,425 /$ ha and peaked $(P<0.001)$ in 2017 at $€ 3,574$ / ha. Net farm profit $(€ /$ ha) was greatest $(P<0.001)$ in 2017 (€1,286/ha) and lowest in 2016 (€629/ha). Net farm profit as a percentage of farm gross output averaged $27.9 \%$ and ranged from $22.9 \%$ in 2016 to $36.0 \%$ in 2017 . Finally, farm net profit was highly variable during the 9 -yr period and was greatest $(P<0.001)$ in 2017 $(€ 89,506)$ because of a combination of factors including milk price, greater pasture utilization, increased dairy specialization, and scale growth. Farm net profit was least $(P<0.001)$ in $2010(€ 39,564)$ because pasture utilization was least, farms were less specialized, and smaller in scale.

\section{Frequency of PM Completion and Farm Physical and Financial Characteristics}

We divided the farms in 4 categories based on their financial benchmarking use frequency. A total of 1,071 individual farmers (representing 7,973 farm years) were frequent PM users, completing financial benchmarking between 7 and 9 times over the 2010 to 2018 period (an average of 7.44 PM completions); 1,492 individual farmers (representing 6,472 farm years) were less frequent PM users, completing financial benchmarking between 4 and 6 over the 9-yr period (an average of $4.34 \mathrm{PM}$ completions); and 3,125 individual farmers (representing 4,971 farm years) were low PM users, completing financial benchmarking between 1 and 3 times over the 9-yr period (an average of 1.59 PM completions). Finally, 257 individual farmers (representing 716 farm 
Ramsbottom et al.: FINANCIAL BENCHMARKING ON DAIRY FARMS AND FARM PERFORMANCE

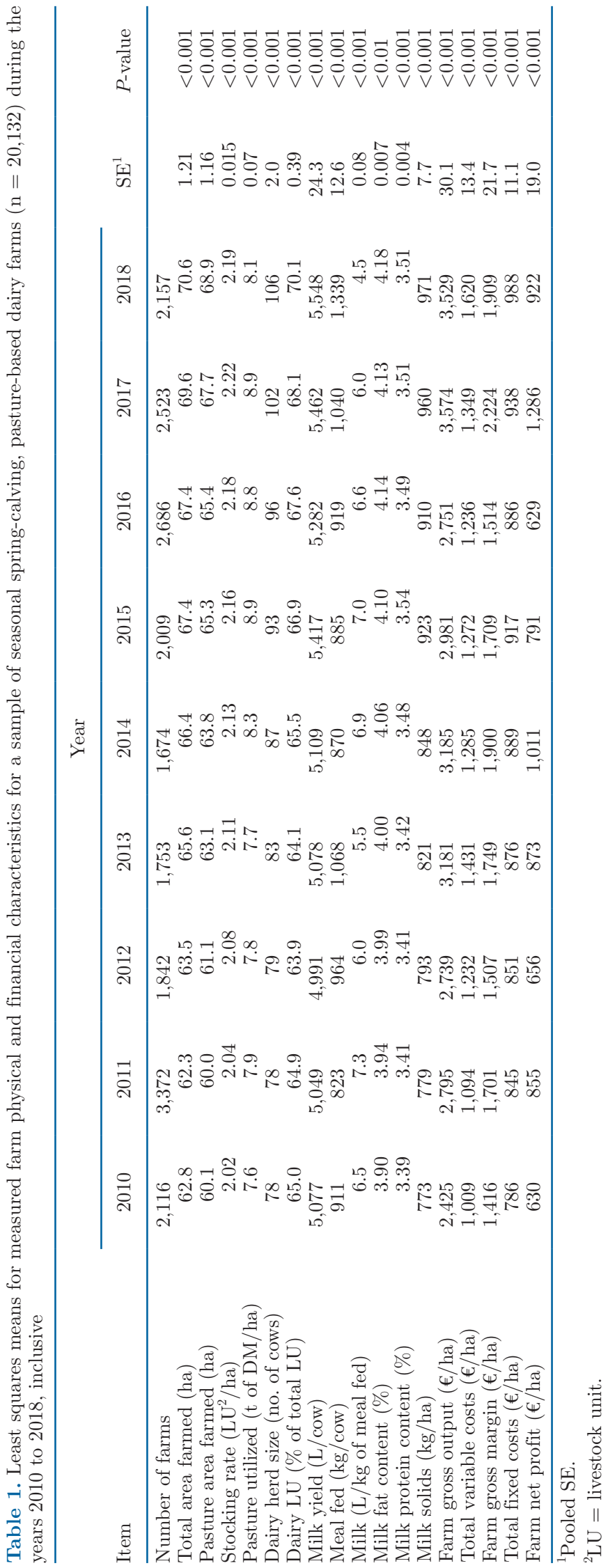

years) were nonusers and did not use financial benchmarking at all during the observation period.

Summary statistics, calculated by the MIXED procedure in SAS for a range of performance measures are presented in Table 2. This table provides least squares means, and associated standard deviations are reported in Supplemental Tables S2 (farm physical) and S3 (financial), respectively (https://doi.org/10 .3168/jds.2020-18843). Again, the last column in Table 2 indicates whether differences across categories were statistically significant. Overall, we observed significant differences across all groups over all farm physical and financial characteristics.

More specifically, compared with the nonuser category, frequent PM users had 12.1 ha larger farms $(P$ $<0.001)$, a 16.6 ha greater area of pastureland $(P<$ $0.001)$, and an average of 39 more cows $(P<0.001$; Table 2). However, heir herd size was considerably more variable than for the nonuser category, averaging $109 \pm 68.3$ cows and $70 \pm 35.8$ cows, respectively (Supplemental Table S2). Compared with the nonusers, the frequent user category was also more efficient when measured by SR $(0.13 \mathrm{LU} /$ ha more; $P<0.001)$, pasture use $(P<0.001)$, milk yield per kilogram of feed $(P<0.001)$, milk solids yield per cow and per hectare (21 kg and $95 \mathrm{~kg}$ respectively; $P<0.001$ ), and fed less meal per cow $(168 \mathrm{~kg} ; P<0.001)$. Farms in the nonuser category were smallest and least efficient, whereas the infrequent and low PM users were in between the 2 extreme categories in relation to their farm physical characteristics.

In relation to financial indicators, by virtue of their greater intensity, the frequent PM users also had the greatest farm gross output per hectare $(P<0.001)$, production costs $(P<0.001)$, and farm net profit $(P<$ 0.001) (Table 2). However, farm net profit per hectare was considerably less variable for the frequent PM user category, averaging €1,091 $\pm 600.7 /$ ha compared with an average of $€ 658 \pm 511.6 /$ ha for the nonuser category (Supplemental Table S3, https://doi.org/10.3168/jds .2020-18843). We also observed that total farm profit increased with the intensity of financial benchmarking use (Table 2).

Next, we explored the specific factors that determine economic performance in each of the PM user categories. Results are reported in Table 3. We used farm gross margins per hectare as our economic performance measure and regressed this measure on farm physical characteristics. We focused on gross margins as opposed to net margins as we hypothesized that PM users were more likely to focus on the improvement of gross margins because many elements of fixed costs such as loan interest or depreciation on investments are not affected greatly by PM use. We tested a nonlinear relationship 
Table 2. Least squares means for measured farm physical and financial characteristics for a sample of seasonal spring-calving, pasture-based dairy farms categorized by frequency of use ${ }^{1}$ of Profit Monitor (PM) during the years 2010 to 2018, inclusive $(\mathrm{n}=20,132)$

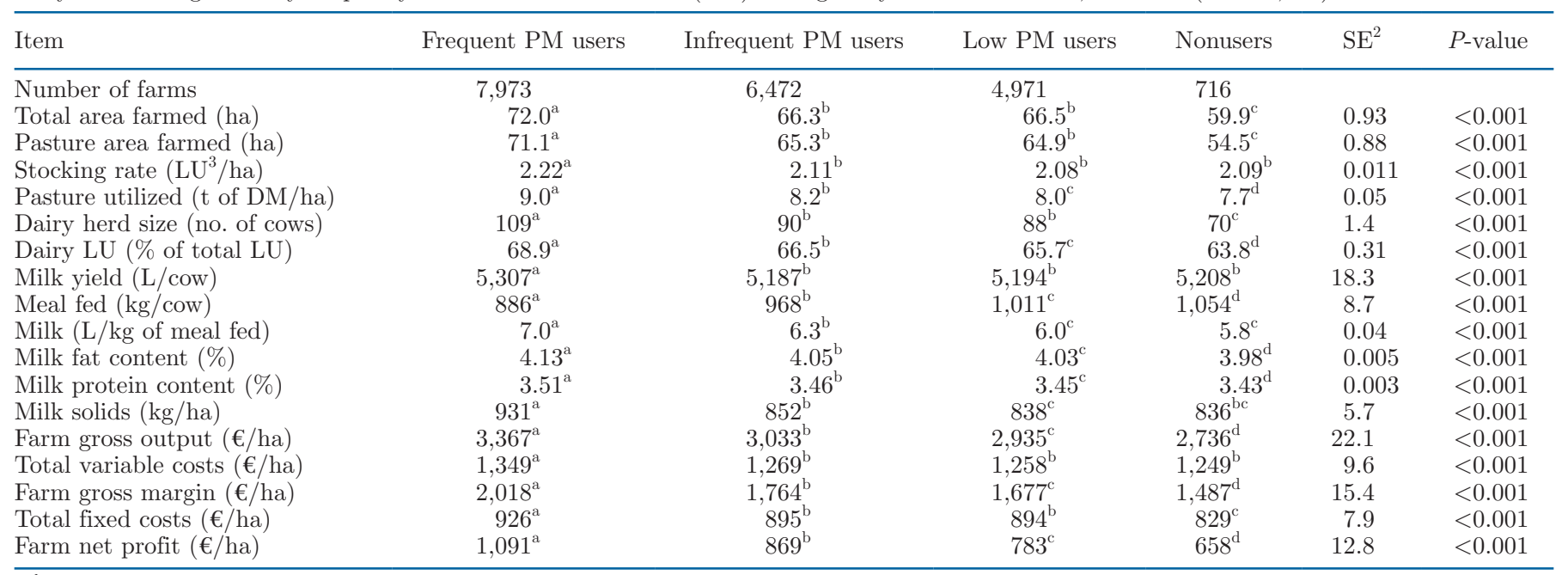

${ }^{\mathrm{a}-\mathrm{d}}$ Means within a row with different superscripts differ $(P<0.05)$.

${ }^{1}$ Farms were categorized by frequency of annual financial benchmarking over the 9-yr period into frequent PM users (7-9 yr), infrequent PM users (4-6 yr), low PM users (1-3 yr), and nonusers.

${ }^{2}$ Pooled SE.

${ }^{3} \mathrm{LU}=$ livestock unit.

of all factors by including a quadratic term, which we retained in the final specification if it was statistically significant $(P<0.10)$. Overall, we found that the same factors were associated with economic performance in each category; however, the magnitude of this effect differed across categories.

More specifically, our findings revealed that farm size (measured as dairy herd size) was not a statistically significant $(P>0.1)$ driver of economic performance. However, dairy specialization showed a significant $(P$ $<0.05)$ positive association with gross margin, but with diminishing effects with increasing specialization in the nonuser group. In addition, our empirical findings revealed that when over $85 \%$ of nonusers' LU are dairy cows, gross margins were predicted to decline. In relation to pasture utilization, we found a statistically significant $(P<0.01)$ positive relationship with gross margins for all categories, with small diminishing effects for the frequent PM user group. This implied that higher environmental sustainability was positively associated with economic returns. Finally, our findings also revealed that meal fed was positively associated with higher economic returns for all groups except nonusers, albeit the effect was rather small.

As our descriptive statistics reported in Table 2 clearly indicate that frequent PM users had larger dairy herds, we explored this effect in more detail. More specifically, we assessed whether there were farms with lower farm

Table 3. Results (robust SE in parentheses) from panel data analysis of factors associated with economic performance by Profit Monitor (PM) use frequency $^{1}$

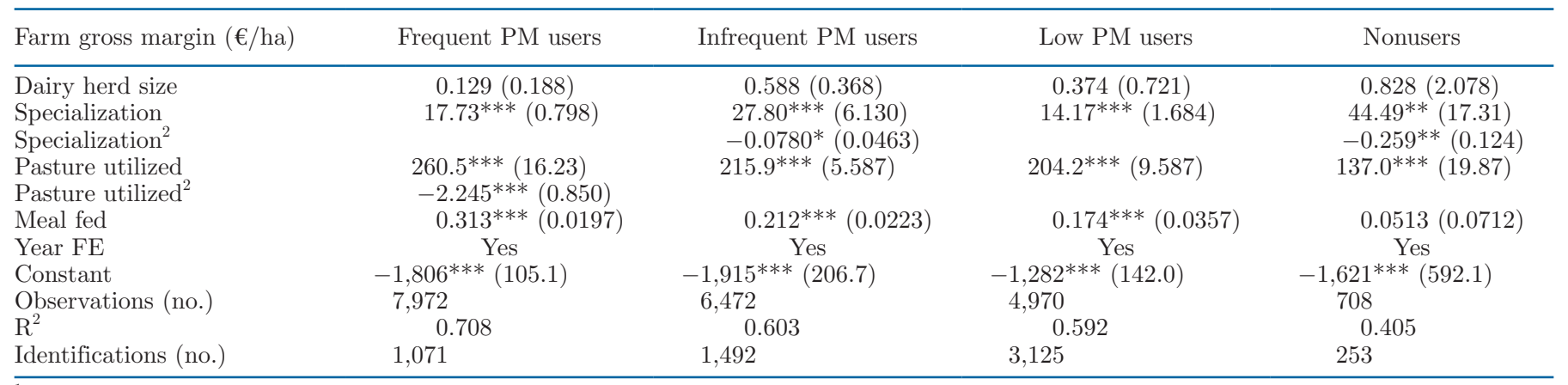

${ }^{1}$ Farms were categorized by frequency of annual financial benchmarking over the 9-yr period into frequent PM users (7-9 yr), infrequent PM users (4-6 yr), low PM users $(1-3 \mathrm{yr})$, and nonusers. $\mathrm{FE}=$ fixed effects.

*** $P<0.01,{ }^{* *} P<0.05,{ }^{*} P<0.1$. 
size within the frequent PM user category that were most economically efficient. For this, we selected the top and bottom quartile of farms in relation to economic performance (gross margins per hectare) and farm size (dairy herd size), respectively. The results revealed that only a small proportion $(2.75 \%)$ of frequent PM users fell into this subgroup. Compared with the remaining frequent PM users, $t$-tests revealed that this subgroup was significantly more specialized in dairy production (73.89 vs. 68.83 ), utilized more pasture (10.19 vs. 8.97), and were also more intensively stocked (2.43 vs. 2.22 ).

\section{Development of Farm Physical and Financial Performance Over Time by PM Use Frequency}

Next, we explored how selected farm physical and financial performance indicators developed over the study period between the different PM user groups. Selected measures of physical performance by year and categories of PM use are presented in Figure 1. In general, we observed significant differences in characteristics in the base year (2010) that developed differently across groups over the observation period.

More specifically, dairy herd size of the frequent PM users was $41.0 \%$ greater in 2010 than herd size of nonusers' farms $(P<0.001)$. Moreover, over the 9 -yr period, herd size increased by the greatest number (43.3 cows) in this category when compared with the other categories, with nonusers having the lowest herd expansion $(P<0.001$; by $13.9 \%$ and 9.1 cows respectively). In addition, frequent PM users had the highest SR and greatest increase $(P<0.001)$ over the study period, whereas the nonusers had the lowest SR and lowest increase over the 9-yr period (3.8\%). The frequent PM users utilized the greatest amount of pasture per hectare in all years $(P<0.001)$ and recorded the greatest increase $(P<0.001)$ in pasture utilization between 2010 and 2017 (1.7 t of DM/ha). The difference in pasture utilization between the most frequent PM user and nonuser categories widened between 2010 (1.2 t of DM/ ha or an $18 \%$ difference) and 2017 (1.8 t of DM/ha or a difference of $23 \%$ ). However, the difference narrowed between the 2 categories in 2018 to $1.1 \mathrm{t}$ of $\mathrm{DM} / \mathrm{ha}$ (14\%), most likely due to the challenges experienced in growing pasture during the summer.

Selected measures of financial performance by year and categories of PM use are presented in Figure 2. Measured per hectare, farm gross output and net profit were greatest $(P<0.001)$ in all years for frequent $\mathrm{PM}$ users, and second greatest for the infrequent PM users. The low PM users and nonusers had lowest farm gross output and net profit. The difference in farm gross output per hectare between the frequent PM user category and nonuser category increased from $€ 473 /$ ha in 2010 to $€ 1,002 /$ ha in 2018. Similarly, the difference in farm net profit/ha between the 2 categories increased from $€ 397 /$ ha in 2010 to $€ 500 /$ ha in 2018 due to intensification and increase in scale of the dairy herd. On a wholefarm basis, the change in farm net profit between 2010 and 2018 was $€ 37,639, € 28,008$, €26,270, and €10,977 for frequent PM user, infrequent PM user, low PM user, and nonuser categories, respectively, with the gap in change in farm net profit between the frequent PM users and nonusers increasing by $€ 22,662$.

\section{Results of the Multinomial Logit Analysis}

The multinomial logit model separated the farmers into the 4 previously described groups to explore the factors that distinguish these groups (Table 4). Overall, the model confirmed that there were significant differences between the groups, which were revealed by a Wald test that rejected the null hypotheses at the $1 \%$ level that any PM user groups can be merged. The Wald test was based on all variables, and the individual coefficient estimates provided detailed insights into the differences between the PM user groups.

The model revealed significant differences between the PM user groups in relation to herd size, with all PM user categories more likely to have larger herds than the nonuser category. In relation to specialization (i.e., the proportion of dairy cows in the livestock herd), there was no significant difference between low PM use and nonuse, but more frequent PM user categories were significantly more specialized than nonusers. The model also revealed that PM users were more likely to have higher single farm payments (SFP) per hectare, although the economic significance of this effect appeared small. This indicated that there was a tendency for more specialized farmers with larger herd sizes and higher SFP per hectare to frequently engage with PM.

In relation to feeding strategies, there was no significant difference in relation to pasture utilization between nonusers and low or infrequent PM use. In contrast, frequent PM users had significantly $(P<0.01)$ higher pasture utilization than nonusers. However, all PM user groups fed significantly less concentrates per cow than nonusers. Finally, we found significant $(P<0.01)$ regional differences in relation to the frequency of PM use. For example, farmers in the south and northwest regions were significantly more likely to engage with PM use than farmers in the east and midlands regions (the base category). Although generally the northwest region was not seen as a typical dairy region, this result can be explained that due to the small number of very committed PM users in the northwest region. 


\section{DISCUSSION}

This analysis provided a unique opportunity that characterized the implications of frequency of financial benchmarking using a common methodology for a large database over an extended timeframe. We used a unique data set comprising 5,945 dairy farms, representing 20,132 farm years, over a 9-yr time period, which included detailed farm physical and financial characteristics. The general trends toward intensifica-

$\leftarrow$ Frequent PM Users $\rightarrow$ Infrequent PM Users $\rightarrow$ Low PM Users $\rightarrow$ Non-users

a)

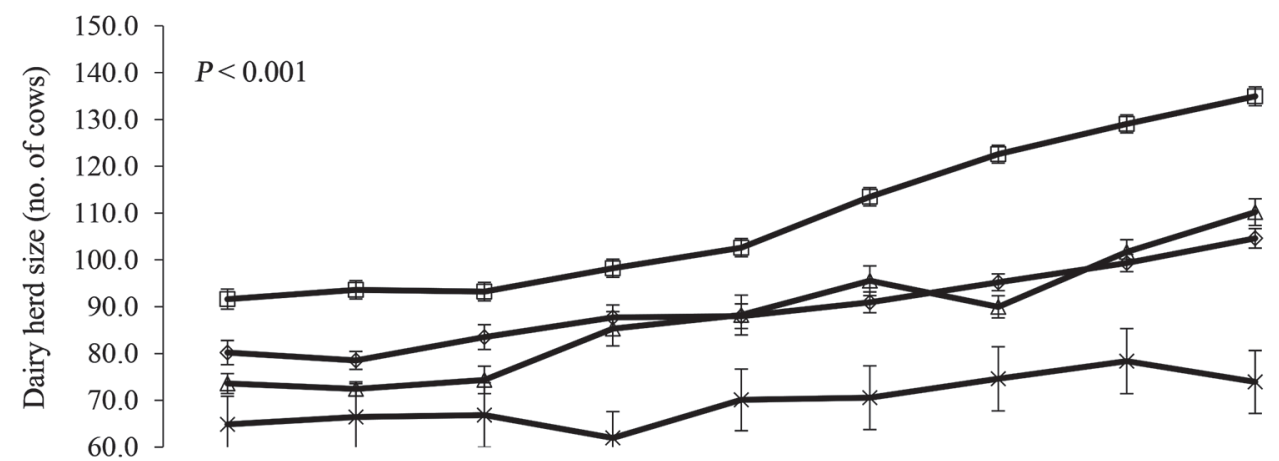

b)

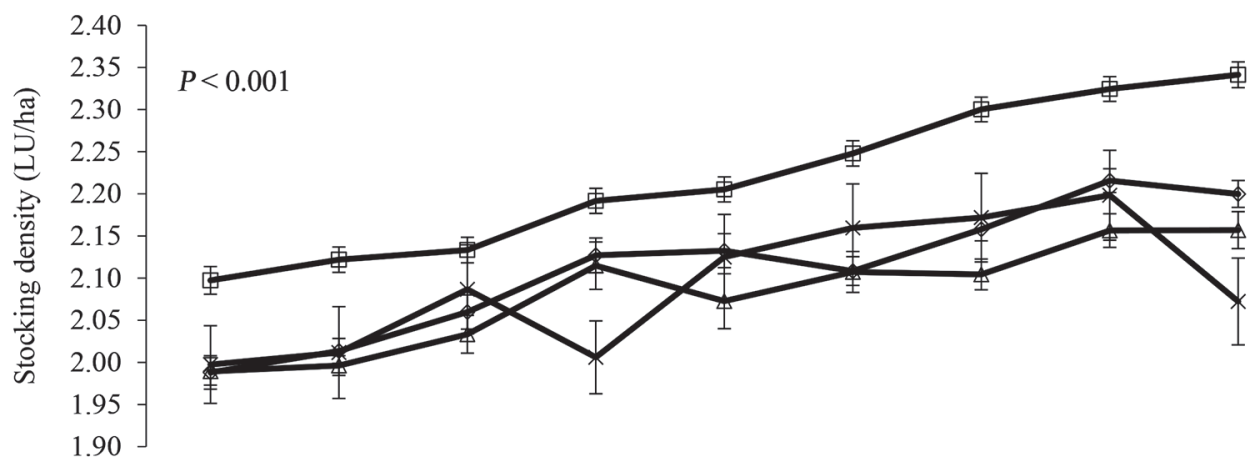

c)

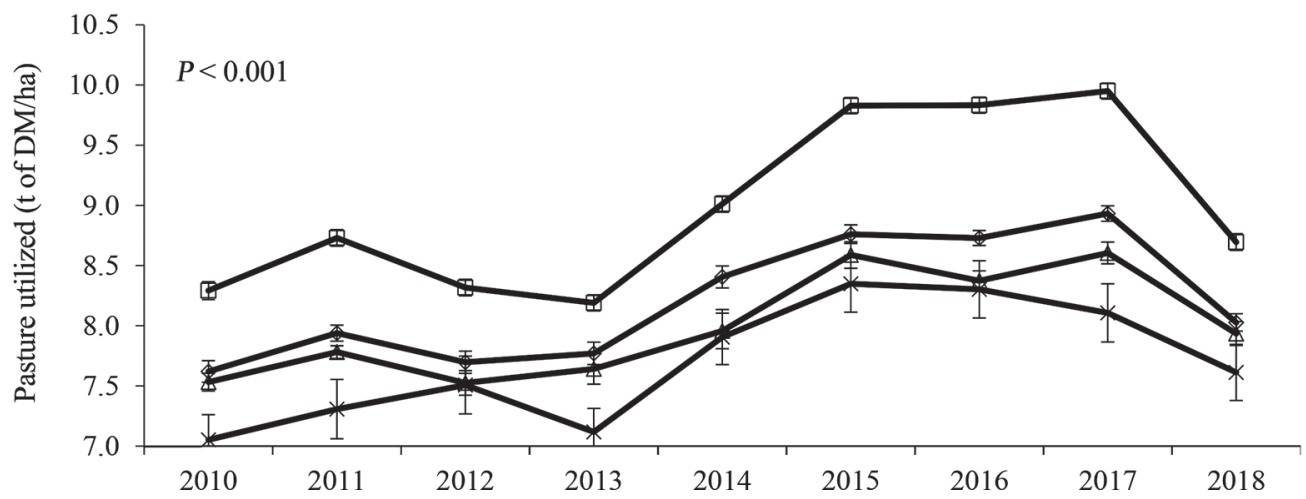

Figure 1. The effect of Profit Monitor completion category on (a) dairy herd size (no. of cows), (b) stocking density (LU/ha), and (c) pasture utilized ( $\mathrm{t}$ of $\mathrm{DM} / \mathrm{ha}$ ). Farms were categorized by frequency of annual financial benchmarking over the 9-yr period into frequent PM users (7-9 yr), infrequent PM users (4-6 yr), low PM users (1-3 yr), and nonusers. Error bars represent SE within completion category. LU = livestock unit. 
$\longrightarrow$ Frequent PM Users $\longrightarrow$ Infrequent PM Users $\leftarrow$ Low PM Users $\rightarrow$ Non-users

a)

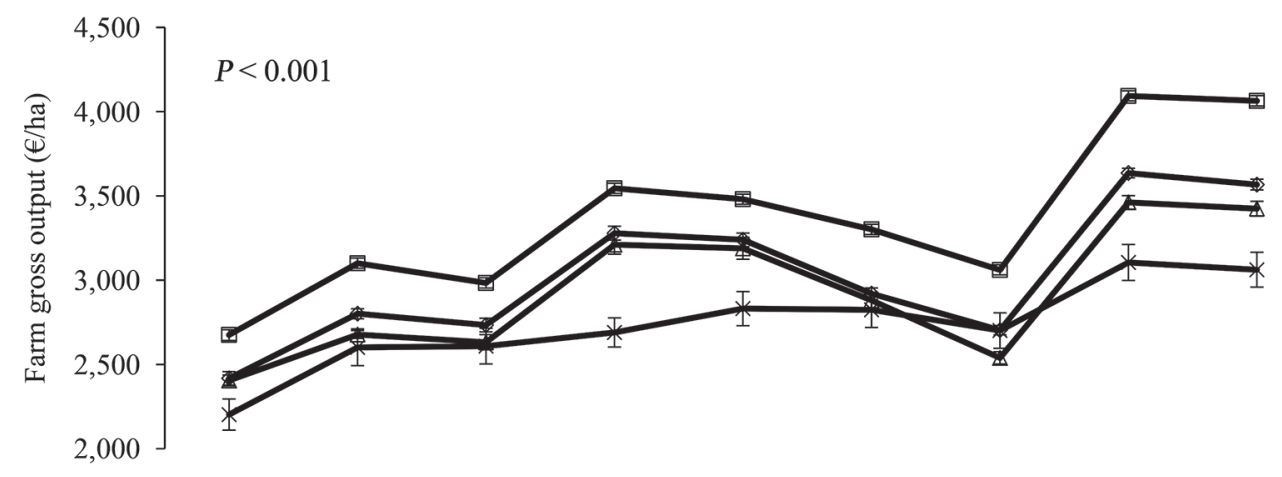

b)

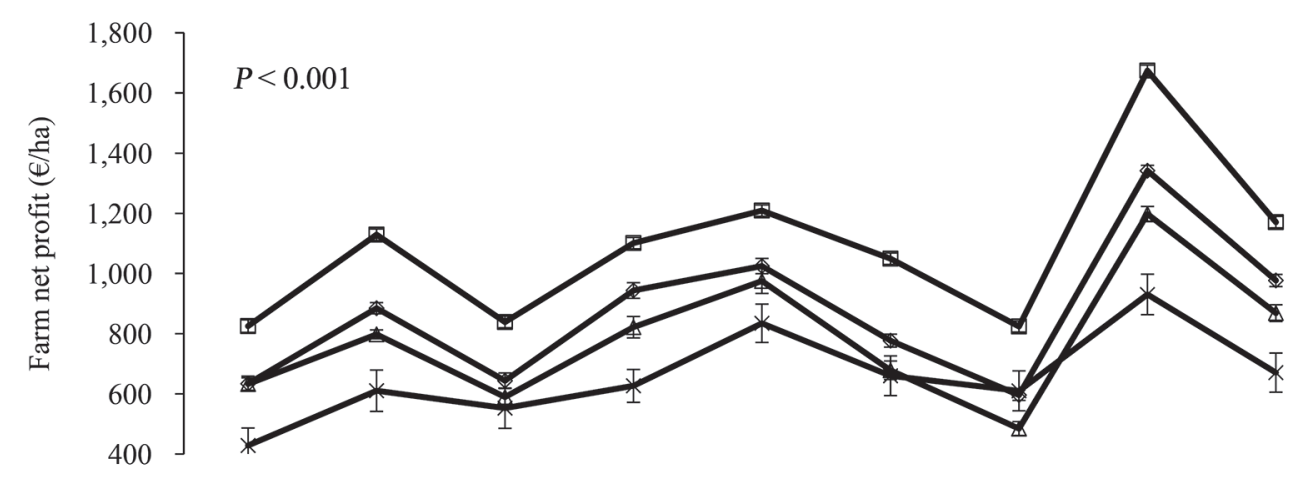

c)

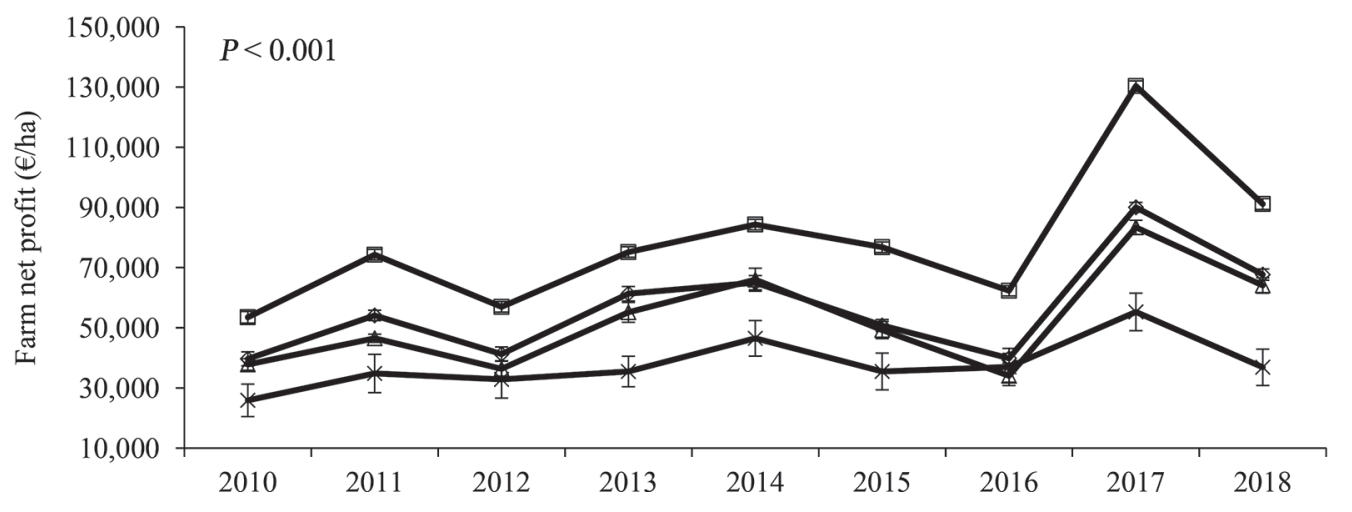

Figure 2. The effect of Profit Monitor completion category on (a) farm gross output (€/ha), (b) farm net profit (€/ha), and (c) farm net profit $(€ /$ farm $)$. Farms were categorized by frequency of annual financial benchmarking over the 9-yr period into frequent PM users (7-9 yr), infrequent PM users (4-6 yr), low PM users (1-3 yr), and nonusers. Error bars represent SE within completion category.

tion, increased operational scale, specialization, and productivity observed within this study (Table 1) were similar to those previously reported for pasture-based dairy industries internationally (DairyNZ, 2019). In
Ireland, this trend has been accelerated by the EU milk quota abolition in 2015.

The current study indicated that there was a positive association between frequency of use of financial 
benchmarking and greater technical (measured by greater milk yield per cow, yield of milk per kilogram of purchased feed and SR), and financial efficiency (measured by greater gross output and net profit; Table 2). Milk per kilogram of feed used can be seen as a measure of resource efficiency, and our findings indicated that more frequent PM use was associated with better resource efficiency. Moreover, there was also a positive association between pasture utilization and PM use frequency. Pasture utilization was closely linked to environmental sustainability, as increasing the amount of grazed grass is an important mitigation measure in the Irish marginal abatement cost curve (Lanigan and Donnellan, 2019).

Our findings also indicated that economic performance was positively associated with specialization and pasture utilization. The latter indicated that an increased focus on environmental sustainability may also imply higher economic returns. This provides a win-win strategy for farmers and society, encouraged by financial benchmarking. Of course, one has to be careful in attributing effects directly to PM use, as generally farmers who decide to use financial benchmarking are also likely to be farmers who are better farm managers and more motivated. Therefore, in the current analysis, financial benchmarking and initial farmer's ability may drive better farm performance. Nevertheless, our study provided important insights on associations.

The study also showed that frequent PM users were better resourced initially (measured by farming scale, SR intensity, and milk yield per cow and per hectare) and had the greatest change over the period investigated (Figure 1). This conclusion was consistent with previous research (Garforth et al., 2004; Hennessy and Heanue, 2012; Forbord and Vik, 2014). Furthermore, frequency of PM use can also be interpreted as an indicator of the level of engagement with advisory services. In this context, the findings confirm that higher levels of engagement with agricultural extension services are positively associated with greater technical and financial change as observed in previous studies (Läpple et al., 2013; Brennan et al., 2016; Nordin and Höjgård, 2017). Finally, frequent PM users had greater SFP per hectare than nonusers (Table 3), which indicated that this category has a history of intensive farming and greater scale as such payments were established almost a decade before the current study period commenced. This finding supports results from Läpple and Hennessy (2015), who found that longer term participants of farm discussion groups were more technologically advanced, had larger scale, more intensive, and more specialized farms than shorter term participants, who were more advanced than nondiscussion group participants

Quota abolition in 2015 facilitated rapid increases in technical efficiency. For example, Kelly et al. (2020) documented substantial technical change in Ireland, and Sipiläinen et al. (2014) observed similar trends on Norwegian dairy farms following the liberalization of agricultural policies. Also of importance in the current study is the increase in scale emerging on dairy farms, which is consistent with that reported in other countries (MacDonald and Newton, 2014; DairyNZ, 2019). Similar to their studies, the findings reported in our study suggest that there is a growing financial gap (Figure 2) between more technically efficient benchmarkers and the nonusers, which is consistent with the variation observed in other countries (AHDB, 2018, AgricultureVictoria, 2019). The likely outcome of this emerging gap is the development of a 2-speed dairy industry comprised of fewer, larger scale farms, as has happened elsewhere (MacDonald and Newton, 2014).

Ongoing financial benchmarking and continued technical improvement are essential to maintaining future competitiveness (McDonald et al., 2016). In an effort to promote increased financial benchmarking, PM completion was a mandatory element of 2 knowledge

Table 4. Multinomial logit analysis of physical and financial variables for frequency of Profit Monitor (PM) use category ${ }^{1}$ compared with nonusers of PM (robust SE in parentheses)

\begin{tabular}{lccc}
\hline Variable & Frequent PM users & Infrequent PM users & Low PM users \\
\hline Dairy herd size & $0.0183^{* * *}(0.0032)$ & $0.0148^{* * *}(0.0032)$ & $0.0139^{* * *}(0.0032)$ \\
Specialization & $0.0256^{* * *}(0.0063)$ & $0.0108^{*}(0.0061)$ & $0.0042(0.0060)$ \\
SFP per hectare & $0.0020^{* * *}(0.0004)$ & $0.0017^{* * *}(0.0004)$ & $0.0009^{* *}(0.0004)$ \\
Pasture utilized & $0.1473^{* * *}(0.0437)$ & $-0.0045(0.0430)$ & $-0.0306(0.0425)$ \\
Meal fed & $-0.0011^{* * *}(0.0002)$ & $-0.0007^{* * *}(0.0002)$ & $-0.0004^{* *}(0.0002)$ \\
Northwest & $2.3961^{* * *}(0.3257)$ & $2.0831^{* * *}(0.3204)$ & $1.9212^{* * *}(0.3123)$ \\
South & $0.9794^{* * *}(0.2493)$ & $1.2000^{* * *}(0.2460)$ & $1.2433^{* * *}(0.2366)$ \\
Year FE & Yes & Yes & Yes \\
Constant & $-3.1017^{* * *}(0.5857)$ & $-1.3364^{* *}(0.5661)$ & $-0.1389(0.5519)$ \\
Observations (no.) & 20,132 S
\end{tabular}

${ }^{1}$ Farms were categorized by frequency of annual financial benchmarking over the 9-yr period into frequent PM users (7-9 yr), infrequent PM users (4-6 yr), low PM users (1-3 yr), and nonusers. FE $=$ fixed effects. *** $P<0.01,{ }^{* *} P<0.05,{ }^{*} P<0.1$. 
transfer programs developed by the Irish Department of Agriculture, which operated in the 2010 to 2012 and 2013 to 2015 periods (Läpple and Hennessy, 2015). It is perhaps not surprising that, without such incentives, financial management technologies have had a low uptake rate among the general farming population. McDonald et al. (2016) found that dairy farmers perceive farm financial management technologies as neither easy to use nor easy to understand. Incentivizing uptake alone without greater simplification of the available financial management technologies will likely not be successful in ensuring their greater adoption and more frequent use.

\section{CONCLUSIONS}

Across a period of profound change within the Irish dairy industry, the results of this study clearly indicate the existence of a strong positive relationship between frequency of financial benchmarking and greater technical and financial efficiency. Our findings also indicate that financial benchmarking is positively associated with environmental sustainability and more efficient use of resources. At the same time, there is substantial evidence of a growing divide in technical and financial efficiency and farm income between cohorts of farms within the industry. Our study suggests that financial benchmarking could provide a means to overcome this growing divide, unless the effect is entirely driven by unmeasured variables such as financial motivation. Nevertheless, to facilitate more widespread use, new approaches are warranted in both the development of simplified financial benchmarking technologies and in supporting their extension to increase their frequency of use. Wider uptake rates may also help to facilitate a more sustainable agri-food sector.

\section{ACKNOWLEDGMENTS}

Brendan Horan (Teagasc, Moorepark, Ireland) is gratefully acknowledged for his invaluable support and contribution. The authors have not stated any conflicts of interest.

\section{REFERENCES}

AgricultureVictoria. 2019. Dairy Farm Monitor Project Victoria Annual Report 2018-2019. DairyAustralia, ed. AgricultureVictoria, Bendigo DC, Victoria, Australia.

AHDB. 2018. Dairy performance results 2016/17. AHDB, Stoneleigh Park, Kenilworth, Warwickshire, UK.

AHDB. 2020. Farmbench. AHDB, Stoneleigh Park, Kenilworth, Warwickshire, UK.

Brennan, N., M. Ryan, T. Hennessy, P. Cullen, and E. Dillon. 2016. Going beyond FADN: The use of additional data to gain insights into extension service use across European Union Member States. Stud. Agric. Econ. (Bp.) 118:145-153. https://doi.org/10.7896/j .1630 .
Byrne, A., T. Kelly, and D. Ruane. 2003. Business management practices on irish dairy farms-The role played by extension. J. Int. Agric. Ext. Educ. 10:5-11. https://doi.org/10.5191/jiaee.2003.10301.

Candler, W., and D. Sargent. 1962. Farm standards and the theory of production economics. J. Agric. Econ. 15:282-290. https://doi .org/10.1111/j.1477-9552.1962.tb01715.x.

CSO. 2020a. AAA06; Farm animals in December by type of animal and year. Central Statistics Office, Ireland. Accessed Apr. 10, 2020. https: / data.gov.ie/dataset/aaa06-farm-animals-in-december -thousand-by-type-of-animal-and-year.

CSO. 2020b. AKM01: Intake of cows milk by creameries and pasteurizers by month, domestic or import source and statistic. Central Statistics Office, Ireland. Accessed Apr. 10, 2020. https://data.gov .ie/dataset/intake-of-cows-milk-by-creameries-and-pasteurisers-by -month-domestic-or-import-source-and-statistic.

DairyNZ. 2019. New Zealand Dairy Statistics 2018-19. DairyNZ, Hamilton, New Zealand.

DairyNZ. 2020. Dairybase. DairyNZ, Hamilton, New Zealand.

Dillon, P., S. Crosse, G. Stakelum, and F. Flynn. 1995. The effect of calving date and stocking rate on the performance of springcalving dairy cows. Grass Forage Sci. 50:286-299. https://doi.org/ 10.1111/j.1365-2494.1995.tb02324.x.

Dillon, P., T. Hennessy, L. Shalloo, F. Thorne, and B. Horan. 2008. Future outlook for the Irish dairy industry: A study of international competitiveness, influence of international trade reform and requirement for change. Int. J. Dairy Technol. 61:16-29. https:// doi.org/10.1111/j.1471-0307.2008.00374.x.

Dowie, C. 2020. Production system key to dairy's woes, says analyst. Farmonline national. ADF News. Accessed May 4, 2020. https:// www.farmonline.com.au/story/6703617/production-system-key-to -dairys-woes/.

Eurostat. 2020. Production of cow's milk on farms by NUTS2 regions. European Commission, Eurostat, L-2920, Luxembourg.

Ferris, A., and B. Malcolm. 1999. Sense and nonsense in dairy farm management economic analysis. Pages $1-31$ in Proc. 43rd Annual Australian Agricultural and Resource Economics Society (AARES) Conference, Christchurch, New Zealand. AARES, The Australian National University, Canberra, Austrailia.

Forbord, M., and J. Vik. 2014. Motivation for increased production among Norwegian farmers. Page 8 in Proc. Farming systems facing global challenges: Capacities and strategies. 11th European IFSA Symposium, Berlin, Germany. International Farming Systems Association (IFSA) Europe. Vienna, Austria.

Garforth, C., T. Rehman, K. McKemey, R. Tranter, R. Cooke, C. Yates, J. Park, and P. Dorward. 2004. Improving the design of knowledge transfer strategies by understanding farmer attitudes and behaviour. J. Farm Manag. 12:17-32.

Hennessy, T., and K. Heanue. 2012. Quantifying the effect of discussion group membership on technology adoption and farm profit on dairy farms. J. Agric. Educ. Ext. 18:41-54. https://doi.org/10 $.1080 / 1389224 X .2012 .638784$

Hennessy, T., T. O'Dwyer, K. Connolly, G. Ramsbottom, and B. Moran. 2015. Costs of production on dairy farms. Pages 38-39 in TResearch. Teagasc, Oak Park, Carlow, Ireland.

IFCN. 2019. Dairy Report: 20th Anniversary Edition. International Farm Comparison Network (IFCN) Dairy Research Center, Kiel, Germany.

Kelly, P., L. Shalloo, M. Wallace, and P. Dillon. 2020. The Irish dairy industry-Recent history and strategy, current state and future challenges. Int. J. Dairy Technol. 73:309-323. https://doi.org/10 $.1111 / 1471-0307.12682$.

Lanigan, G., and T. Donnellan. 2019. An Analysis of Abatement Potential of Greenhouse Gas Emissions in Irish Agriculture 20212030. Accessed Aug. 7, 2020. https://www.teagasc.ie/media/ website/publications /2018/An-Analysis-of-Abatement-Potential -of-Greenhouse-Gas-Emissions-in-Irish-Agriculture-2021-2030.pdf.

Läpple, D., and T. Hennessy. 2015. Exploring the role of incentives in agricultural extension programs. Appl. Econ. Perspect. Policy 37:403-417. https://doi.org/10.1093/aepp/ppu037.

Läpple, D., T. Hennessy, and C. Newman. 2013. Quantifying the economic return to participatory extension programmes in Ireland: 
An endogenous switching regression analysis. J. Agric. Econ. 64:467-482. https://doi.org/10.1111/1477-9552.12000.

MacDonald, J., and D. Newton. 2014. Milk Production Continues Shifting to Large-Scale Farms. USDA, Washington, DC.

McDonald, R., K. Heanue, K. Pierce, and B. Horan. 2016. Factors influencing new entrant dairy farmer's decision-making process around technology adoption. J. Agric. Educ. Ext. 22:163-177. https://doi.org/10.1080/1389224X.2015.1026364.

Neal, M., and J. R. Roche. 2020. Profitable and resilient pasturebased dairy farm businesses in New Zealand. Anim. Prod. Sci. 60:169-174. https://doi.org/10.1071/AN18572.

Nordin, M., and S. Höjgård. 2017. An evaluation of extension services in Sweden. Agric. Econ. 48:51-60. https://doi.org/10.1111/agec .12294 .

O’Sullivan, M., B. Horan, K. M. Pierce, S. McParland, K. O'Sullivan, and F. Buckley. 2019. Milk production of Holstein-Friesian cows of divergent Economic Breeding Index evaluated under seasonal pasture-based management. J. Dairy Sci. 102:2560-2577. https:// doi.org/10.3168/jds.2018-15559.

Parker, W. J. 1998. Standardisation between livestock classes: The use and misuse of the stock unit system. New Zealand Grassland Association 60:243-248. https://doi.org/10.33584/jnzg.1998.60.2277.

Parker, W. J. 1999. Farm performance measurement-Linking monitoring to business strategy. Proc. N.Z. Soc. Anim. Prod. 59:6-13.

Patton, D., L. Shalloo, K. Pierce, and B. Horan. 2012. A biological and economic comparison of 2 pasture-based production systems on a wetland drumlin soil in the northern region of Ireland. J. Dairy Sci. 95:484-495. https://doi.org/10.3168/jds.2011-4558.

Ramsbottom, G., A. R. Cromie, B. Horan, and D. P. Berry. 2012. Relationship between dairy cow genetic merit and profit on commercial spring calving dairy farms. Animal 6:1031-1039. https:// doi.org/10.1017/S1751731111002503.
Ramsbottom, G., B. Horan, D. P. Berry, and J. R. Roche. 2015. Factors associated with the financial performance of spring-calving pasture-based dairy farms. J. Dairy Sci. 98:3526-3540. https://doi .org/10.3168/jds.2014-8516.

Ramsbottom, G., B. Horan, K. M. Pierce, and J. Roche. 2020. Dairy expansion: A case study of spring-calving pasture-based dairy production systems in Ireland. J. Agr. Sci. 1-10. https://doi.org/10 .1017/S0021859620000696.

SAS. 2005. SAS/STAT User's Guide. SAS Institute Inc., Cary, NC.

Sipiläinen, T., S. C. Kumbhakar, and G. Lien. 2014. Performance of dairy farms in Finland and Norway from 1991 to 2008. Eur. Rev. Agric. Econ. 41:63-86. https://doi.org/10.1093/erae/jbt012.

Teagasc. 2015. The end of the quota era: A history of the dairy sector and its future prospects. Page 30. T. Donnellan, T. Hennessy, and F. Thorne, ed. Teagasc, Athenry, Galway, Ireland.

Teagasc. 2019a. Profit Monitor Analysis-Dairy Farms 2018. Teagasc, Oak Park, Carlow, Ireland. https://www.teagasc.ie/publications/ 2019/profit-monitor-analysis---dairy-farms-2018.php.

Teagasc. 2019b. National Farm Survey. Teagasc, Oak Park, Carlow, Ireland. https://www.teagasc.ie/publications/2019/teagasc -national-farm-survey-2018-results.php.

Teagasc. 2020. National Farm Survey. Teagasc, Oak Park, Carlow, Ireland. https://www.teagasc.ie/publications/2020/teagasc-national -farm-survey-2019-preliminary-results.php.

Wooldridge, J. M. 2010. Correlated random effects models with unbalanced panels. Michigan State University, Department of Economics, Lansing MI. 